\title{
Geometric morphometrics for the study of hemicoxae sexual dimorphism in a local domestic equine breed
}

\author{
PARÉS-CASANOVA, P. M.* \\ Department of Animal Production, University of Lleida, Av. Alcalde Rovira Roure 191, 25198 Lleida (Catalunya), Spain \\ ${ }^{*}$ E-mail: peremiquelp@prodan.udl.cat
}

\begin{abstract}
Introduction and material and methods. Twenty-height skeletonised hemicoxae from young animals (yearlings, 13 males and 15 females) belonging to the "CavallPirinencCatalà" horse (Catalan Pyrenean Horse) breed were studied by means of geometric morphometric (GM) methods. Morphometric analysis was based on coordinates of 16 landmarks of the ilium and ischiopubic regions that were digitised on 2D photographic images. Sexes did not appear separated either by size or shape, the latter being independent of the former.K-means clustering of shape variables were used in order to classify individuals by sex and an average accuracy of $\mathbf{5 7 . 1 \%}$ was achieved. Results. Males were misclassified more frequently than females. For the iliac landmarks, which contributed to the total variance of shape with the higher degree, the value obtained increased to $60.7 \%$ for $\mathrm{k}$-means. The ischiopubic complex contributed less to sex differentiation according to shape. Conclusion. It is concluded that the use of GM and multivariate statistics is not a reliable method to quantify pelvic shape and size differences between the sexes for equine yearlings. This is the first known study to apply GM to the hip of an equine breed.
\end{abstract}

Keywords: animal ethnology, “Cavall Pirinenc Català”, Catalan Pyrenean Horse, hipbones.

\section{Introduction}

In recent years, functional studies incorporating geometric morphometric (GM) analyses have become increasingly common (e.g. ROHLF, LOY and CORTI, 1996; ROSAS and BASTIR, 2004; OETTLÉ, PRETORIUS and STEYN, 2005). Since GM techniques have been discussed at length elsewhere (see SLICE, 2005), a detailed discussion is not necessary here. Procrustes superimpositionbased techniques such as relative warps analysis offer an advantage over traditional analyses of linear morphometrics in that geometric shape space presents all various shape configurations of designated landmarks (BOOKSTEIN, 1996; ROHLF, LOY and CORTI, 1996; ROHLF, 1998). Shape variables (partial and relative warp scores) are particularly constructive in studies that are primarily focused on functional adaptation and evolutionary change in extant and extinct taxa (SINGLETON, 2002; NICHOLSON and HARVATI, 2006).

GM analyses the relative positions of anatomical landmarks and sets of points used to approximate curves (outlines) and surfaces to quantify size and shape (JENSEN, 2003). The geometric information of shape differences is preserved, statistical power is increased (ROHLF and MARCUS, 1993) and patterns can be visualised using image rendering and a variety of other diagrams (ADAMS, SLICE and ROHLF, 2004). In taxonomy and other fields, genetics and morphometrics can fruitfully interact as complementary tools to understand the origin of phenotypic differences (KLINGENBERG, 2010). The number of publications using GM outside biology has increased exponentially and pays testament to the success of this set of methods. However, this type of analysis has not yet been extensively performed in domestic mammals.
Horses are sexually dimorphic animals, with a general pattern of males larger than females. Most research has been done on a pure biometrical basis of linear measurements so the animal ethnologist has no information on shape, apart from size, and/or on testing hypotheses about shape differences. Primarily, studies to measure size are based on univariate proxies such as skull length, or directly as body length or body mass. Although these descriptors of size are useful when discussing overall body size dimorphism, they do not represent shape, and therefore do not fully describe differences between males and females, nor do they typically address sexual differences occurring in specific body regions (SCHUTZ, POLLY, KRIEGER et al., 2009). The pelvis is considered to be a part of the skeleton that presents a large sexual dimorphism (DE PANAFIEU, 2011). Many parts of the human pelvic bones have been studied, such as the great sciatic notch (JOVANOVIC and ZIVANOVIC, 1965; JOVANOVIC, ZIVANOVIC and LOTRIC, 1973; SINGH and POTTURI, 1978; HAGER, 1996), the cranial border (GOMEZ and FERNANDEZ, 1992), the obturator foramen (BIERRY, MINOR and SCHMITTBUHL, 2010) and the entire bone (MILNE, 1990). Pelvic studies have also been carried out in nonhuman anthropoids (GINGERICH, 1972; HAGER, 1996) and also in species such as dog (SAJJARENPONG, ADIRECKTHAWORM, SRISUWATTANASAGUL et al., 2003), grey foxes (SCHUTZ, POLLY, KRIEGER et al., 2009), the northern water vole (VENTURA, GOZÁLBEZ and GÓTZENS, 1991), the mouse (UESUGI, SATO and IGUCHI et al., 1993), whales (BEJDER and HALL, 2002) and bat (NWOHA, 2000), but no detailed studies of the 
bovine obturator foramen are available in the veterinary literature.

Catalan Pyrenean Horse $(\mathrm{CPH})$ is a livestock that is racially very mixed, and physical characteristics are not uniform within the group. $\mathrm{CPH}$ has a compact stocky body and they have kept qualities of adaptation to their living conditions:rusticity, sexual precocity, good fertility, easy births and good mothering skills. They live on the open range throughout the year with a simple handling system:continuous pasturing, natural mating, unassisted birth, foals raised with mares, and sudden weaning of 6-8-month-old foals. All previous morphological researches with this breed have been done at a linear morphometric level.

This research intended to assess differences in sex-specific ilium and ischiopubic (henceforth "hemicoxae") regions" shape and size-shape based on 2D GM.

\section{Materials and Methods}

Twenty-height skeletonised hemicoxae from young purebred animals ( 13 young males and 15 young females; average age 271 days) belonging to the $\mathrm{CPH}$ breed were sampled from an industrial abattoir. No animal presented an abnormal general appearance or signs of clinical lameness before slaughtering. After commercial deboning of carcass, hemicoxae were collected, dissected and cleaned by the authors. All pieces were undamaged and showed no pathological appearance that might lead to errors in measurement. The specimens are now housed in the University of Lleida (Catalunya, Spain).

\subsection{Image acquisition}

Image capture was performed with a Nikon ${ }^{\circledR}$ D70 digital camera (image resolution of 2,240 x 1,488 pixels) equipped with a Nikon AF Nikkor ${ }^{\circledR} 28-200$ mm telephoto lens. The focal axis of the camera was parallel to the horizontal plane of reference and centred on the obturator foramen. The same distance was used for all photographs. No distinction was made between right and left samples.

\subsection{Morphological characterisation}

Hemicoxae were photographed and on each picture there were digitised sixteen landmarks. The medial plan (MP) of each piece was photographed using a standard procedure with a tripod-mounted digital camera. Hemicoxae were photographed once with the same procedure. The MP is an interesting structure as it perfectly reflects many muscles that attach on this plane, such as obturatorius internus, iliacus, psoas minor, erector spinae, etc. (BARONE, 1999).

Morphometric analysis must be based on unambiguous and repeatable anatomical marks. The pelvic girdle consists of two symmetrical hip bones (ossa coxae), which meet ventrally at the pelvic symphysis (symphysis pelvina). Each hip bone is composed of three parts with separate ossification centres:ilium (os ilium), pubis (os pubis) and ischium (os ischii). The chosen landmarks represented different points from the hemicoxae and were chosen because of their easiness to locate on fixed bony points and moreover that they are distributed between the three bones that form the coxae (ilium, pubis and ischium). Sixteen landmarks were collected for each specimen. In addition to being highly repeatable, these landmarks encompass elements of the entire hemicoxae (Figure 1).

Shape variables were obtained as linear combinations of the original landmark coordinates after standardising size and removing artefactual variation due to different positions of the specimens in the process of data collection (generalised Procrustes analysis). Size information was retained as centroid size (CS). CS is the size measure for landmark configurations. Shape differences were visualised with deformation grids, where an object (reference) is deformed into another (target) and shape features can be described in terms of deformation grids depicting the differences between objects (ADAMS, SLICE and ROHLF, 2004). The thin plate spline (TPS) algorithm was used to compute the deformation grid with least bending energy between reference and target landmark configurations.

Landmarks were digitised twice using tpsDig 2.04 (life. bio.sunysb.edu/ee/rohlf/ software.html). Landmark positions were converted to scaled $\mathrm{x}$ and $\mathrm{y}$ coordinates and CS extracted using CoordGen6f (www.canisius.edu/sheets).

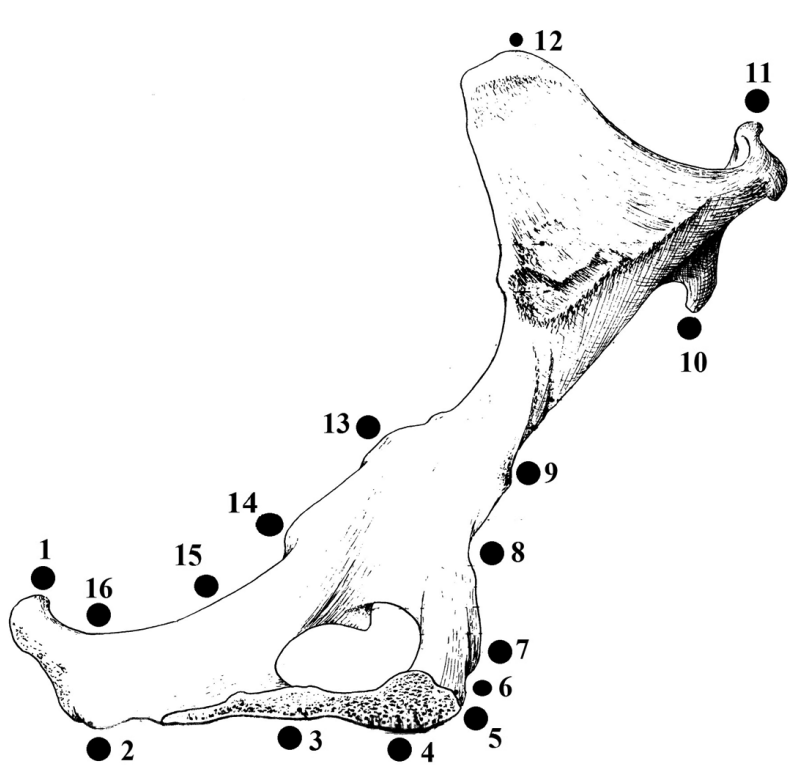

Figure 1. Sixteen landmarks used in the analyses. Medial plan of the hemicoxae. 1. Dorso-caudal point of the ischial tuber (insertion of $m$. gluteobiceps). 2. Crest of the ischial tuber (insertion of $m$. ischiocavernous). 3. Vertical projection of the caudal part of the obturator foramen to the most ventral ramus of the ischium. 4. Vertical projection of the most cranial point of the obturator foramen to the most ventral ramus of the ischium. 5. Most cranial point of the pubic tuberosity (insertion of tendon prepubic). 6. Ventral point of the ilio-pubic eminence (insertion of $m$. pectineus). 7. Ilio-pubic eminence (insertion of m. pectineus). 8. Tubercle of $m$. psoas minor. 9. Middle part of the neck of the ilium (insertion of $m$. iliac). 10. Dorso-cranial point of the ventro-craneal iliac (insertion of $m$. iliac). 11 . Most ventral point of the crest of the ilium (insertion of $m$. erector of spina). 12. Most dorsal point of the dorso-craneal iliac spine (insertion of $m$. erector of spina). 13. Projection of the most cranial point of the obturator foramen on the greater sciatic notch 14. Ischiatic spine (insertion of elevator of anus). 15. Most cranial point of the lesser sciatic notch. 16. Most caudal point of the lesser sciatic notch. 
A Mantel test based on Euclidean distances between the Procrustes matrices from each of the two repetitions ( 5,000 permutations) reflected $\mathrm{R}=0.851, \mathrm{p}<0.0001$, which suggested that the matrix entries were positively associated and so digitising error was considered negligible.

To assess differences in shape, a principal-component analysis (PCA) was performed. PCA was used to characterise the main features of shape variation. Non-parametric multivariate (NPMANOVA) analysis was used in order to compare shapes between sexes and a Student's t test was used to compare sizes. Values of CS were log-transformed. Shape variables were regressed onto the first two PCA axes to illustrate shape changes along them. Finally, a K-means clustering (BOW, 1984) was used to test non-hierarchically the differences between sexes. Significance was accepted at $\mathrm{p}=0.05$ level.

\subsection{Numerical statistical analysis}

Data was analysed using the MorphoJ (KLINGENBERG, 2011) and PAST- "Paleontological Statistics Software Package for Education and Data Analysis" (HAMMER, HARPER and RYAN, 2001) software.

\subsection{Ethics statement}

No specific permits were required as this study involved the use of bones of slaughtered animals for commercial purposes external to the purpose of this study.

\section{Results and Discussion}

The first component PCl accounted for $46.2 \%$ of the variation. Iliac points (landmarks 10 to 12 ) contributed to the total variance with the higher degree. The second component PC2 accounted for $13.8 \%$ of the variation and was a measure of the ventral ischium point, i.e. landmark 4 (Table 1 and Figure 2).

Variation in size was similar among sexes (CV 2.4 and $3.1 \%$ for males and females respectively) and there appeared to be no shape differences between sexes ( $\mathrm{F}=1.636$, $\mathrm{p}$ (same) $=0.139)$. K-means clustering of shape was used in order to classify individuals by sex. Average accuracy was of $57.1 \%$. Males were misclassified more frequently than females. For the iliac landmarks (10 to 12$)$, the value
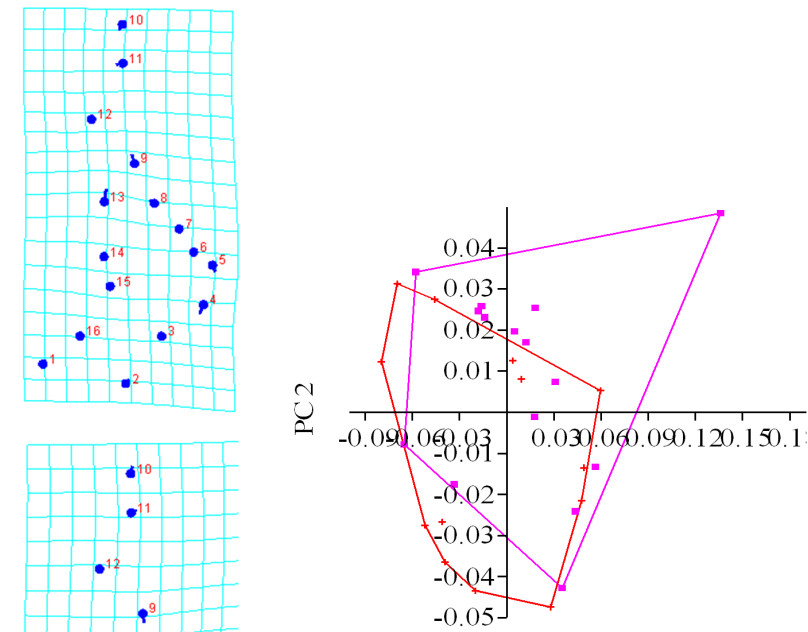

$\mathrm{PC} 1$
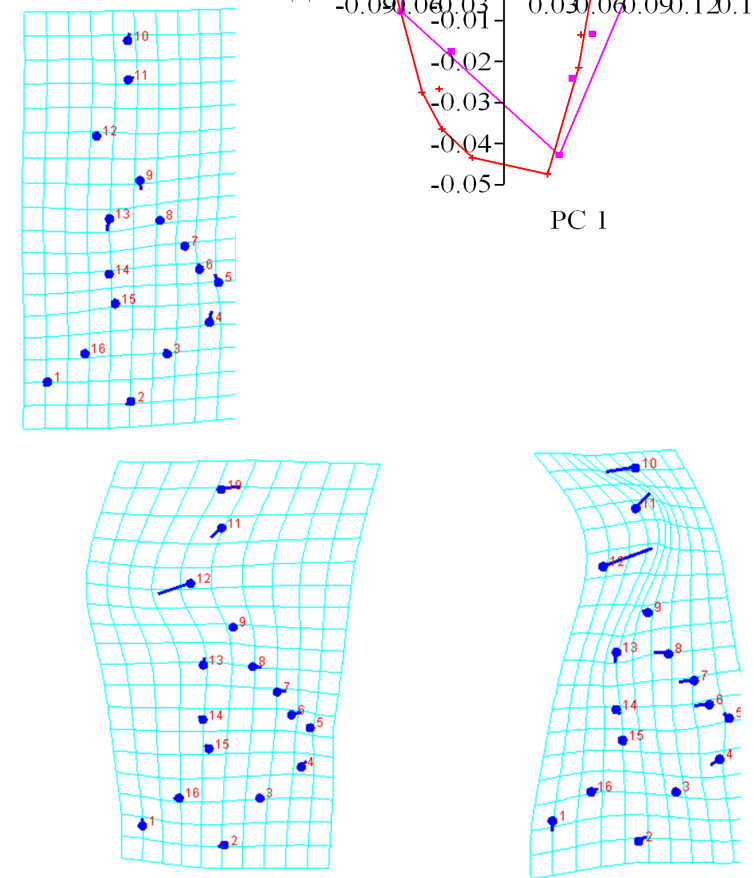

Figure 2. Scatter plot of the scores from Principal Component Analysis for PC1 and PC2. PCl accounted for $46.2 \%$ of the observed variance and PC2 for $13.8 \%$. Diagrams represent hemicoxae shapes over extreme PCl and 2 scores. Iliac points contributed to the total variance of $\mathrm{PCl}$ with the higher degree and the ventral ramus of ischium point to PC2.

Table 1. Eigenvalues from a Principal Component Analysis ( 12 first PCs) treating the hemicoxae ( $\mathrm{n}=28$ ) as the object of interest and the lineal measurements as the variables. No PCs presented eigenvalue $>1$.

\begin{tabular}{cccc}
\hline PC & Eigenvalues & \% Variance & Cumulative \% \\
\hline 1 & 0.00240050 & 46.211 & 46.211 \\
2 & 0.00071833 & 13.828 & 60.039 \\
3 & 0.00054442 & 10.480 & 70.519 \\
4 & 0.00036729 & 7.071 & 77.590 \\
5 & 0.00023014 & 4.430 & 82.020 \\
6 & 0.00017963 & 3.458 & 85.478 \\
7 & 0.00014142 & 2.722 & 88.200 \\
8 & 0.00012280 & 2.364 & 90.564 \\
9 & 0.00008955 & 1.724 & 92.288 \\
10 & 0.00007342 & 1.413 & 93.702 \\
11 & 0.00005946 & 1.145 & 94.846 \\
\hline
\end{tabular}




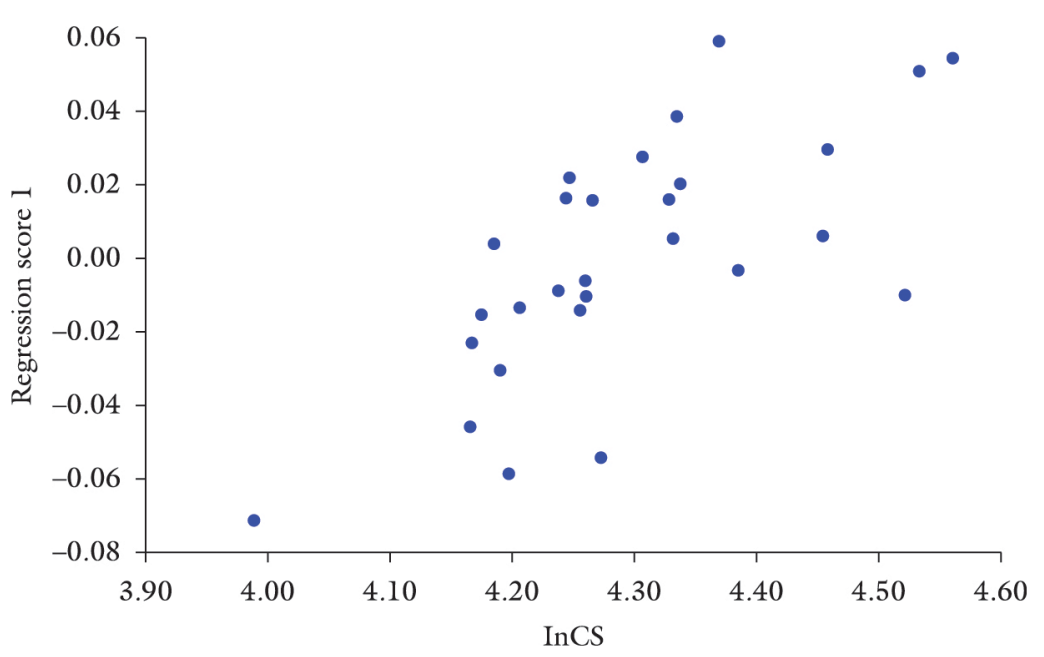

Figure 3. Correlation between ln centroid size (CS) and shape. Interindividual allometry explained a small percentage (10.4\%) of shape differences according to size.

obtained with shape variables was $60.7 \%$. For the ischiopubic complex (landmarks 1 to 7 , and 14 to 16 ) the value obtained with shape variable reduced to $46.4 \%$. Ln CS was not significantly different among sexes $(\mathrm{F}=1.775, \mathrm{p}$ (same $)=$ $0.07)$. Interindividual allometry explained a small percentage (10.4\%) of shape differences according to size (Figure 3 ).

\section{Conclusion}

We can draw some preliminary conclusions regarding the amount of significance of shape and size variation in coxae of CPH animals. Firstly, a very small error demonstrated that the proposed landmarks can be located with precision and that images are acquired with accuracy, despite the lack of flatness of the medial plan. The individual variation for size was similar for both sexes. Current opinion regards the hipbone as the most reliable sex indicator because it is the most dimorphic bone. In the case of this study, the fact that differences in shape and size did not appear can be considered normal as the fusion of the three bones that form the hipbone occurs at about 10-12 months of age in equines (BARONE, 1999), which is more than the age of our studied animals.

This is the first known study to apply GM to the equine pelvic bones, so comparison of our data to other published sources is not possible. We advocate further GM studies in domestic breeds in order to compare populations, and the exchange of information between research centres. Regarding methodology, specialists of ethnology must be aware of the lack of diagnostic power when using traditional morphometrics. GM is based on photographs, so the same individual can be repeatedly analysed, and no need for storage of biological specimens is necessary. Moreover, lineal measurements directly on bones are time consuming and cannot be re-measured if necessary.

Acknowledgements: Thanks to the abattoir MAFRISEU SA from where samples and their associated information were obtained. Oriol Marsà and Sara Martínez helped to prepare bones.

\section{References}

ADAMS, DC., SLICE, DE. and ROHLF, FJ. Geometric morphometrics: Ten years of progress following the 'revolution'. Italian Journal of Zoology, 2004, vol. 71, p. 5-16. http://dx.doi. org/10.1080/11250000409356545

BARONE, R. Anatomie compare des mammifêres domestiques. Paris: Vigot, 1999.

BEJDER, L. and HALL, BK. Limbs in whales and limblessness in other vertebrates: mechanisms of evolutionary and developmental transformation and loss. Evolution \& Development, 2002, vol. 4, n. 6, p. 445-458. PMid:12492145. http://dx.doi.org/10.1046/ j.1525-142X.2002.02033.x

BIERRY, G., LE, MINOR, JM. and SCHMITTBUHL, M. Oval in males and triangular in females? A quantitative evaluation of sexual dimorphism in the human obturator foramen. American Journal of Physical Anthropology, 2010, vol. 141, p. 626-631. PMid:19927366

BOOKSTEIN, FL. Combining the tools of geometric morphometrics. In: MARCUS, LF., CORTI, M., LOY, A., NAYLOR, GJP. and SLICE, DE. (Eds.). Advances in morphometrics. New York: Plenum, 1996. p. 131-151.

BOW, ST. Pattern recognition. New York: Marcel Dekker, 1984. PMCid:PMC1875734

DE PANAFIEU, JB. Evolution. New York: Seven Stories Press, 2011.

GINGERICH, PD. The development of sexual dimorphism in the bony pelvis of the squirrel monkey. The Anatomical Record, 1972, vol. 172, p. 589-596. PMid:4622200. http://dx.doi. org/10.1002/ar.1091720312

GOMEZ, L. and FERNANDEZ, FJ. Biometry of the cranial border of the human hip bone: normal values and their use in sex determination. Journal of Anatomy, 1992, vol. 181, p. 417-422.

HAMMER, Ø., HARPER, DAT. and RYAN, PD. PAST: Paleontological statistics software package for education and data analysis. Palaentologia Electronica, 2001, vol. 4, n. 1, p. 1-9.

HAGER, LD. Sex differences in the sciatic notch of great apes and modern humans. American Journal of Physical Anthropology, 1996, vol. 99, p. 287-300. http://dx.doi.org/10.1002/(SICI)10968644(199602)99:2<287::AID-AJPA6>3.0.CO $2-\mathrm{W}$ 
JENSEN, RJ. The conundrum of morphometrics. Taxon, 2003, vol. 52, p. 663-671. http://dx.doi.org/10.2307/3647340

JOVANOVIC, S. and ZIVANOVIC, S. The establishment of the sex by the great schiatic notch. Acta Anatomica, 1965, vol. 61, p. 101-107. http://dx.doi.org/10.1159/000142684

JOVANOVIC, S., ZIVANOVIC, S. and LOTRIC, N. A study of sex-determined characteristics of the hip bones in pathologically deformed female pelves using the method of Sauter and Privat. Acta Anatomica, 1973, vol. 84, p. 62-73. http://dx.doi. org/10.1159/000143910

KLINGENBERG, CP. Evolution and development of shape: integrating quantitative approaches. Nature Review Genetics, 2010, vol. 11, p. 623-635. PMid:20697423

KLINGENBERG, CP. MorphoJ: an integrated software package for geometric morphometrics. Molecular Ecology Resources, 2011, vol. 11, p. 353-357. http://dx.doi.org/10.1111/j.17550998.2010.02924.x

MILNE, N. Sexing of human hip bones. Journal of Anatomy, 1990, vol. 172, p. 221-226. PMid:2272904 PMCid:PMC1257217

NICHOLSON, E. and HARVATI, K. Quantitative analysis of human mandibular shape using three-dimensional geometric morphometrics. American Journal of Physical Anthropology, 2006, vol. 131, p. 368-383. PMid:16617436. http://dx.doi. org/10.1002/ajpa.20425

NWOHA, PU. Sex differences in the bony pelvis of the fruit-eating bat, Eidolon helvum. Folia Morphologica, 2000, vol. 59, p. 291295.

OetTlé, AC., PRETORIUs, E. and STEYN, M. Geometric morphometric analysis of mandibular ramus flexure. American Journal of Physical Anthropology, 2005, vol. 128, p. 623-629. PMid:15861427. http://dx.doi.org/10.1002/ajpa.20207

ROHLF, FJ. On applications of geometric morphometrics to studies of ontogeny and phylogeny. Systematic Biology, 1998, vol. 7, p. 147-158.

ROHLF, FJ., LOY, A. and CORTI, M. Morphometric analysis of old world talpidae (Mammalia, Insectivora) using partial-warp scores. Systematic Biology, 1996, vol. 45, p. 344-362. http://dx.doi. org/10.1093/sysbio/45.3.344
ROHLF, FJ. and MARCUS, LF. A revolution in morphometrics. Trends in Ecology and Evolution, 1993, vol. 8, p. 129-132. http:// dx.doi.org/10.1016/0169-5347(93)90024-J

ROSAS, A. and BASTIR, M. Geometric morphometric analysis of allometric variation in the mandibular morphology of the hominids of Atapuerca. Sima de los Huesos site. The Anatomical Record, 2004, vol. 278, Pt A, p. 551-560.

SAJJARENPONG, K., ADIRECKTHAWORM, A., SRISUWATTANASAGUL, K., SUKJUMLOG, S. and DARAWIROJ, D. Differences seen in the pelvic bone parameters of male and female dogs. Thai Journal of Veterinary Medicine, 2003, vol. 33 , n. 4 , p. 55-61.

SCHUTZ, H., POLLY, PD., KRIEGER, JD. and GURALNICK, RP. Differential sexual dimorphism: size and shape in the cranium and pelvis of grey foxes (Urocyon). Biological Journal of the Linnean Society, 2009, vol. 96, p. 339-353. http://dx.doi.org/10.1111/ j.1095-8312.2008.01132.x

SINGH, S. and POTTURI, BR. Greater sciatic notch in sex determination. Journal of Anatomy, 1978, vol. 125, p. 619-624. PMid:640963 PMCid:PMC1235628

SINGLETON, M. Patterns of cranial shape variation in the Papionini (Primates: Cercopithecinae). Journal of Human Evolution, 2002, vol. 42, p. 547-578. PMid:11969297. http:// dx.doi.org/10.1006/jhev.2001.0539

SLICE, DE. Modern morphometrics in physical anthropology. New York: Kluwer Academic, 2005.

UESUGI, Y., SATO, T. and IGUCHI, T. Morphometric analysis of the pelvis in mice treated neonatally with tamoxifen. The Anatomical Record, 1993, vol. 235, n. 1, p. 126-130. PMid:8417621. http:// dx.doi.org/10.1002/ar.1092350113

VENTURA, J., GOZÁLBEZ, J. and GÓTZENS, VJ. The os coxae of a digging form of the northern water vole, Arvicola terrestris (Rodentia, Arvicolidae). Anatomia, Histologia, Embryologia, 1991, vol. 20, n. 3, p. 225-236. PMid:1759723. http://dx.doi. org/10.1111/j.1439-0264.1991.tb00299.x

Received November 11, 2013 Accepted December 18, 2014 